off. These experiments under hypnosis suggest that if a patient can be hypnotised deeply enough and pain be abolished the healing process would be greatly facilitated. This might apply not only to surgical conditions, but also to medical conditions such as pleurisy. Pain is a very valuable indicator to point us to physical disorder or injury, but this seems to exhaust its function, and its abolition, either by the surgical means suggested by Hilton or, if possible, by hypnotic means, would conduce to greater rapidity in healing.

(b) The regulation of the blood-supply: It is a wellknown fact that hyperæmia may be produced by suggestion. The experiments made in producing blisters show to what lengths this regulation of the blood-supply can go in a susceptible patient. This seems to indicate that when we know more about hypnotic suggestion, and have attained a greater skill in inducing it in a larger proportion of patients, we may be able to affect for good any organic inflammatory condition whether medical or surgical, both by regulating the blood-supply (imitating Bier's congestion method, for instance) and also by the abolition of pain.

I do not suppose for a moment that these experiments will convince those who are unacquainted with hypnotic work, and some of whom deny even the existence of hypnotism altogether. But they were conducted under the strictest scientific conditions, and were such as to satisfy the surgeons, of whom there were eight or nine, who had a share in them. Moreover, in order to show my good faith in the matter, I am quite prepared to repeat the experiments under any conditions that may be considered necessary, when the exigencies of war permit of $\mathrm{mg}$ doing so, provided I can obtain the consent of the patient, to whose endurance during several hours of pain I am indebted for the opportunity of conducting the experiments, and by whose permission, as well as that of the Surgeon-General of the Royal Naval Hospital, Chatham, I am enabled to publish them.

\section{A CASE OF}

\section{EPILEPSY CURED BY REMOVAL OF CALCAREOUS INTRACRANIAL TUMOURS.}

\section{BY THEODORE THOMPSON, M.D. CANTAB.}

F.R. C.P. LOND., F.R.C.S. ENG.,

PHYSICIAN TO THE LONDON HOSPITAT AND THE HOSPITAX FOR SICK CHILDREN, GREAT ORMOND-STREET ; CONSULTING PHYSICIAN

TO KING EDWARD FII. HOSPITAL FOR OFFICERS, ETC. AND

ALBERT J. WALTON, M.S., F.R.C.S. ENG., M.B. B.SC. LOND.,

CAPTAIX, R.A.M.C. (T.) ; ASSISTANT SURGEON, LONDON HOBPITAL.

APART from Jacksonian epilepsy-that is, attacks which indicate a definite cerebral place of origin of the convulsionthere are a numerous group of diseases where attacks may occur which simulate the features of so-called idiopathic epilepsy. These may occur in conditions of general blood poisoning such as arise from intoxications by lead, arsenic, alcohol, morphine, or from uræmic states. They may also occur in diffuse diseases of the brain, such as dementia paralytica, multiple sclerosis, cerebral syphilis, or meningitis. A careful consideration of the history and general signs exhibited by the patient will, as a rule, exclude these cases of epileptiform attacks consequent on general blood poisoning or diffuse cerebral disease. There remains, however, a small group of cases where typical epileptiform attacks may be the result of a small local lesion of the brain. The lesion may be so situated that no indication is given of its situation by the nature of the convulsions, and the differentiation of these cases from true idiopathic epilepsy will depend on the mental state of the patient. In the latter condition there appears in the majority of cases a gradual transformation of the entire psychic being, affecting the intelligence of the patient (epileptic degeneration), and in the severe forms of the disease terminating in a condition of marked dementia. It follows that in any chronic case of epilepsy, in which the character and intelligence of the patient are maintained at their normal level, a most careful investigation shopld be made to endeavour to discover a local cerebral lesion which might be the cause of the epileptiform attacks. In the majority of cases no definite lesion is found and there are but few cases on record in which operative treatment aiming at the removal of a localised lesion has been followed by successful results. In this respect it is important to remember that any operation upon the head or even upon any other part of the body may be followed by complete relief of the epilepsy for several weeks with subsequent recurrence of the fits, and unless this fact be borne in mind one is prone to believe that such an operation has removed the causative factor of the fits.

In the following case of what was apparently a chronic condition of epilepsy dating from childhood, but in which there was only slight evidence of change in character or mental condition, an examination of the skull by the $X$ rays revealed the presence of a calcareous mass in the temporosphenoidal lobe, the removal of which has caused a complete cessation of the epileptiform seizures for the past two and a half years. The details of the case are as follows :-

R. S., male, aged 23, was sent to the hospital with a note from the physician stating that he had had epilepsy for many vears and asking whether a radiograph of the skull might throw any light on the condition present. The patient stated that ever since the age of 4 he had had fits. He had kep' a careful account of these fits and stated that there had been six major ones and 193 minor ones. In the major fits there was a definite aura a few minutes before the attack. During the fit he would fall, be quite unconscious, and would bite his tongue. There was no incontinence. This was followed by a period of prolonged sleepiness, and after this by a severe headache. In the minor fits there would be a slight warning and a sensation of giddiness. He would not fall, but nearly always uttered an involuntary cry. The attack would pass off in a half to one minute, but would leave him a little drowsy. When a child he had a course of bromides with good effect, and lately this has been repeated, but the drug seems now to be of but little value in controlling the attacks.

No history could be obtained as to the condition of his health at the onset of the fits, and there was no evidence of any severe lesions such as meningitis. He has found lately that he has been unable to do mental work, especially mathematics, and for the last two years his memory has been poor. He now finds he is less able to do physical work. He tried a course of farming in Canada, but was unable to continue with it. There was no family history of epilepsy or other nervous disease, and he and his parents were total abstainers. On examination there was no evidence of mental deterioration, and, in fact, his intelligence was rather above the average. There were no physical signs in the motor or sensory systems, and his eranial nerves showed no change. There was some deafness on the right side, but this did not appear to be due to any change in the internal ear. The vascular and respiratory systems were normal.

Owing to the request of the physician a radiograph of the head was taken, and it was then seen that there were two large apparently cancellous bony masses attached to the upper and posterior aspects of the right petrous bone. (Fig. 1.) The more anterior of these was somewhat pedunculated and projected into the cavity of the skull for a distance of 1 to $1 \frac{1}{2}$ inches. The nature of these tumours was somewhat doubtful, for although they appeared to be formed of cancellous bone, it was realised that osteomata within the skull are nearly always dense and of the so-called ivory variety. In view of this appearance and the right-sided deafness a report on the condition of the ear was requested from Mr. Hunter Tod. He kindly examined the patient, and reported that there was slight middle-ear deafness on the right side. The seventh and eighth nerves were not affected, and he did not think that the deafness was due to the bony growth.

The patient was admitted to the medical service on May 31st, 1915, and was transferred to the surgical service on June 16th following. During this period he had five or six fits a day, nearly all, however, of the minor variety. On June 16th an operation was performed. After preliminary injection of morphia and atropine and under ether anæesthegia a large osteoplastic flap was made in the right temporal region. The bone flap was square in outline, the size of the square measuring 3: inches. The flap was made by cutting four holes through the skall with a trephine and uniting these trephine openings by means of a Gigli's saw, the underlying dura being carefully protected. The dura at the base of the skull was carefully elevated from the middle fossa until the bony mass was reached. It was then seen that these projected into the dura, their irregular surfaces being very adherent to the thinned-out dura. An attempt to free the dura from them soon showed that this would not be possible, even although a certain amount of the temporal bone and greater wing of the sphenoid was removed below 
F זs. 1 .

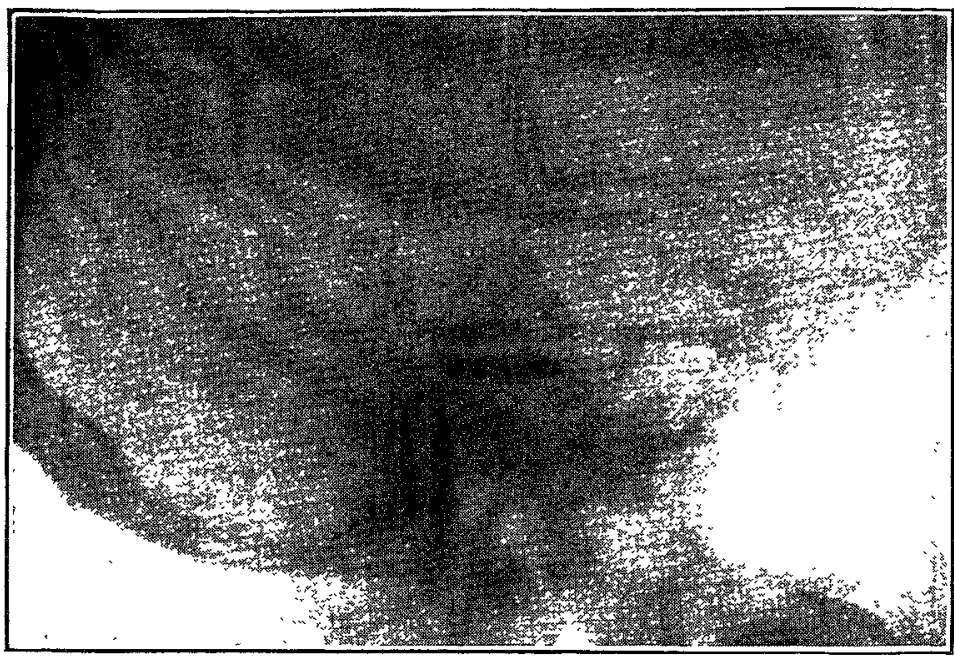

Lateral view of skull showing $\mathrm{b}$ my $\llcorner$ umours attached to petrous bone.

the level of the osteoplastic flap. The dura was therefore freely opened and the temporal lobe elevated by wide malleable copper retractors. By this means a very good view of the tumours was obtained, and it was seen that they projected into pits in the brain lined by pia arachnoid, having, in fact, much the same relationship to the brain as is found in cases of endotheliomata of the dura. With care it was possible to entirely free them from the brain, this latter structure being gradually elevated. The thinned-out overlying dura was then incised and the tumours gradually freed down to their point of attachment to the petrous bone. By pressure they were then easily broken off the petrous bone, the surface of which was smoothed with a chisel. The brain was then allowed to drop back into place, the dura was sutured, and the osteoplastic flap replaced in position. The portions of bone removed consisted of two separate tumours, the larger of which had been attached anteriorly. This was about $1 \frac{1}{2}$ inches in diameter, was roughly lobulated, and was covered with fragments of dura. (Fig. 2.) With a knife the outer surface was felt to be formed of bone. The smaller tumour, which had been attached sligbtly posteriorly, was about three quarters of an inch in its longest diameter and was rather smoother. (Fig. 2.) It also apparently consisted of hard bone. The tumours were sawn in half, and it was then seen there was only a thin outer casing of bone with a few septa, the centre portion consisting of a rather firm caseous-like material. Portions of the tumour were decalcified and cut, and Dr. H. M. Turnbull reported "calcareous impregnation of psammoma bodies and formation of lamellar bone in periphery of necrosed angiofibroma of dura of petrous bone." The stitches were removed on the tenth day, there being primary union of the wound. The bony flap was in good position, as there had been no increase of intracranial pressure. (Fig. 3.) He had had no fits since the operation.

On July 7th he was discharged from hospital to the convalescent home in good health, the wound being firmly healed.

FIG. 3.

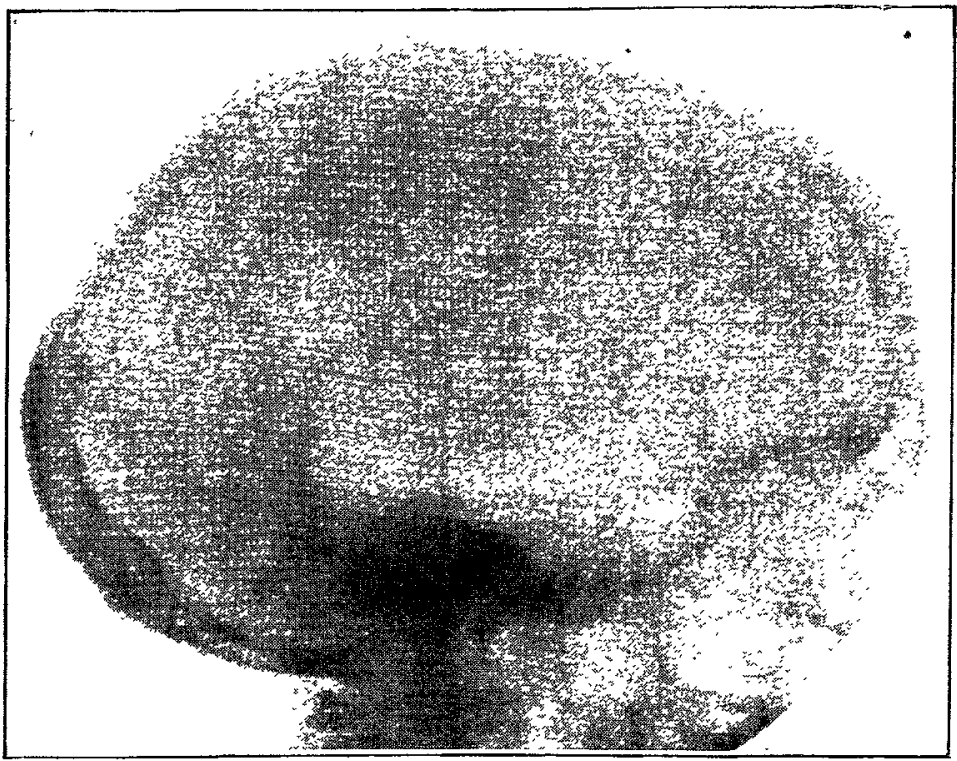

Lateral view of skull showing bony flap replaced in position.
Fir: 2

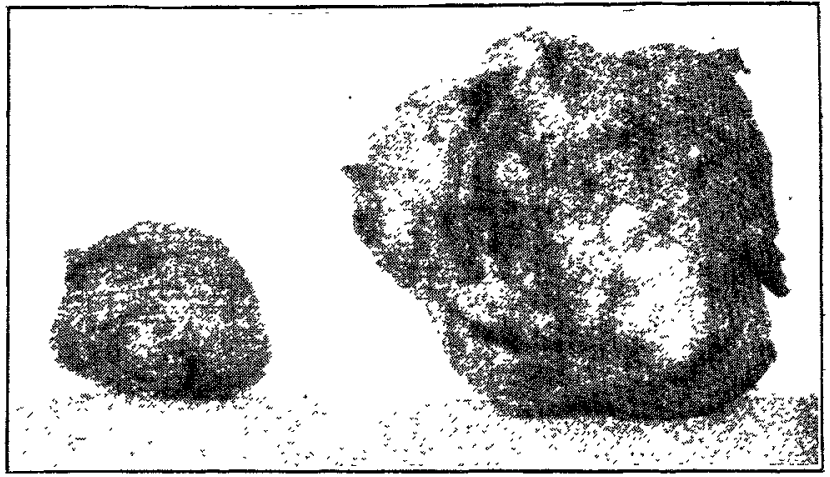

Photograph of tumours after removal.

On Oct. 6th-that is, four months after the operation-he was seen again. There had been no return of the fits, although in the interval he had been taking no bromides. There was no pain in the head and the flap fitted perfectly and firmly. The radiograph showed that union was taking place at the edges of the flap, and there was no evidence of any irregularity on the upper surface of the petrous bone.

Oct. 10th, 1916: Since the operation there have been no fits. He has been in perfect health and has been engaged in business for eight months. $\mathrm{He}_{e}$ is able to carry this out satisfactorily and is never troubled with Joss of memory or inability to do mathematics. The long flap is in perfect position and the trephine openings feel much smaller. There is no tenderness at the site of the operation.

April 24th, 1917: He still feels perfectly well and is free from all symptoms. He is able to carry out his work perfectly and feels in every way a normal man. He has had no fits or minor attacks since the operation. The scar is invisible; the trephine openings can barely be felt, and the $X$ ray photograph (Fig. 4) shows considerable new growth of bone at the site of the trephine openings and the edges of the flap, which is firmly united in position.

That the fits were due to the presence of the tumours is quite clear. At first it was feared that the improvement was temporary and was die to the shock of the operation, a condition often seen when operations are performed on any part of the body of an epileptic. He has now, however, been carefully watched for a period of over two years and during the whole of this period has not had a single attack either of the major or the minor variety. His mental condition and his memory are good, and his power of application has greatly increased, so that there is now every probability that he is permanently cured.

FIG. 4.

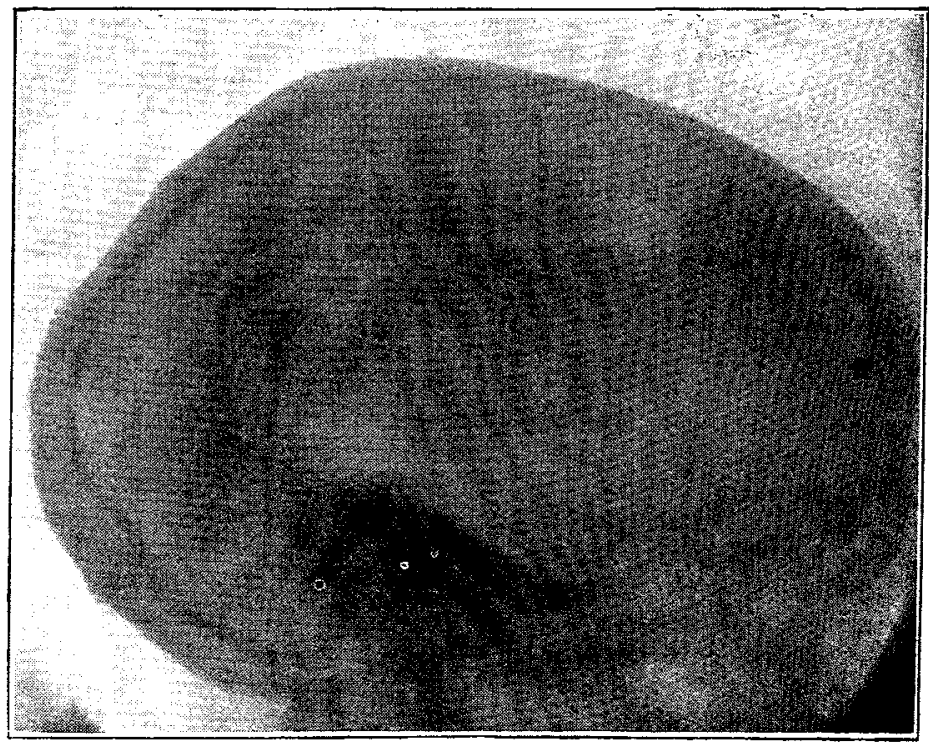

Lateral view $24 / 4,17$ showing bonv plate uniting at edges. Trephine holes decreasing in size. 


\section{Antedical Socteties.}

\section{MEDICAL SOCIETY OF LONDON.}

\section{The Use of Nitrous Oxide and Oxygen with Regulated Rebreathing in Military Surgery.}

A MEETING of this society was held on Oct. 29tb, Sir StClaIr Thomson, the President, being in the chair.

Captain H. EDMUND G. Boyle, R.A.M.C. (T.), read a paper on Experiences in the Use of Nitrous Oxide and Oxygen with Regulated Rebreathing in Military Surgery at the 1st London General Hospital. His paper appears in full on p. 667 of our present issue.

Colonel D'Arcy Power confirmed all Captain Boyle had said from the surgeon's point of view. He asked what amount of experience it was necessary for an anæsthetist to have before using the method on a large scale. Unless care were taken the patient was likely to come out from the anæsthetic, as it was on the light side.

Dr. DUDLEY BUXToN said that before using the method much care and experience were necessary, and he emphasised the importance of rebreathing. There were two schools: one held that there was always some cyanosis, the other that cyanosis was dangerous and should be avoided. He agreed with the latter and considered that cyanosis was not a necessary accompaniment of anæsthesia, and cyanosed cases were always worse afterwards. He thought it better to give the alkaloids an hour before the operation, and laid stress on the importance of silence during induction, for which there should be a separate room.

Mr. HeRBERT PATERSon said that he was associated with Captain Boyle at Queen Alexandra's Hospital for Officers, Highgate. One drawback to the method was that when gas and oxygen were given for abdominal operations patient suffered severe pain for about 12 hours afterwards. He thought the reason was that the intestine was not paralysed, as is the case after ether and chloroform, so that peristalsis continues for longer; but morphia could be given. One great advantage was the absence of nausea, which might last three days after the administration of ether. He then alluded to the very slight post-operative rise of temperature. After clean operations, performed under aseptic conditions, some rise of temperature was regarded as usual, but he had come to the conclusion, after working at Highgate, that speaking of clean operations only-the average post-operative rise of temperature with gas and oxygen was one degree lower than in similar operations in London performed under chloroform and ether. Mr. Paterson then showed temperature charts of patients operated on for appendix and hernia, illustrating the difference in temperature between those who had gas and oxygen and those who had chloroform and ether. In the former the highest temperature was $99^{\circ} \mathrm{F}$., whereas in the latter it usually rose to about $100^{\circ}$. In some cases in which gas and oxygen had been given there was no rise of temperature at all. He thought there was no comparison between gas and oxygen in experienced hands and chloroform and ether. Gas and oxygen were first given for long operations in 1895, but since then the technique was much improved. The late Sir Frederic Hewitt and Mr. Bellamy Gardner used it in 1895, and it was re-discovered in America in 1897. He considered it most difficult to give. Six months' or even a year's experience was needed before it could be given satisfactorily from the surgeon's point of view. I might make the operation more difficult to do, but the patient was safer and was more comfortable afterwards, and fatalities were less frequent.

Colonel H. J. WARING said that, owing to the very short time nteded for induction, much of the surgeon's time was saved. The following classes of case were suitable for gas and oxygen: (1) Septic cases, and patients requiring severe operations; (2) operations on patients who were extremely ill, as there was very little shock; (3) operations on old people, as there was not the same danger of bronchitis. The method was not suitable for muscle-splitting operations, such as operations on the gall-bladder, but was good for operations for enlarged prostate and septic operations. He thought that the small amount of suffering by the patient was a very important point, and he gave instances illustrating very quick recovery from the anæsthetic.
Mr. J. H. CHALDECOTT said that his own experience of gas and oxygen dated from the publication of Crile's paper in this country. It was then used combined with local anæsthesia, and he had so used it at St. Mary's for abdominal operations. He considered it good combined with local anæsthesia; the gas and oxygen provided unconsciousness; the local anæsthetic provided anæsthesia. He never gave gas and oxygen alone for gall-bladder operations, but combined with novocaine it was excellent and gave no aftertrouble. Referring to the management of cases, he said that (1) a good airway should be ensured before starting; (2) there should be silence during the induction and during anæsthesia; and (3) the anæsthetic should be continued until the patient was on the trolley and not stopped while he was still on the operating-table, or he would come round. He thought it was important that the patient should be placed in position for operation before induction.

Mr. MCADAM ECCLES objected to the tooth-prop as patients complained of it. He wished to know something of the cost of the method as compared with ether and chloroform. He thought the weight of the apparatus would make it inconvenient for use in many instances, such as for operations performed in private houses. Owing to the quantity required, gas might run ont in the middle of the operation. What could be done under such circumstances? He thought the afterpains were due to the intestine not being paralysed and peristalsis still going on. He found that hot water in rubber bottles placed on the abdomen relieved pain. $\mathrm{He}$ insisted on the need for quiet before induction and thought the alkaloids were important in this connexion. The patient should never be touched during induction by anjone but the anæsthetist, and should be placed for preference on the operating-table before induction. The rapidity of induction allowed this without loss of time to the surgeon.

Dr. F. K. SHIPWAY said that one point not touched upon was that rebreatbing introduced a new element-namely $\mathrm{CO}_{2}$ which acted as a stimulant to the respiratory centre, and therefore produced a different type of anæsthesia. He asked what was the percentage of $\mathrm{CO}_{2}$ in the bag, and said that with an increase of $\mathrm{CO}_{2}$ and diminution of oxygen a heart was being stimulated which was already starved of oxygen and would easily become dilated. In America a good many deaths were known to have occurred under gas and oxygen. He suggested that the percentage of $\mathrm{CO}_{2}$ in the bag should be worked out. He thought the stimulation of medullary centres by $\mathrm{CO}_{2}$ was the cause of vomiting during and after anæsthesia; the amount of $\mathrm{CO}_{2}$ should be reduced as much as possible. There was urgent necessity for research in anæsthesia, both scientific and physiological, and money was needed to carry it out.

Mr. HUGH LETT thought that gases should be heated and that the administration of unheated gases might be the cause of the bronchitis which occurred.

Mr. BELLAMY GARDNER said there was great danger in trying to rely solely on gas and oxygen. When vomiting occurred during anæsthesia it was not possible to overcome the consequent closing of the air-passages by narcotising the vomiting centre further, as could be done by ether or chloroform. He thought the advantages of the method were not compensated for by the disadvantages of which the patient was ignorant.

Dr. HUGH R. PHillips said the effect of gas and oxygen combined with local anæsthesia depended upon the method of local anæsthesia employed. If complete in all layers the resnlt was very good. Silence was of more importance in this method than in any other; the patient should be placed on the table some time before induction was begun. The disadvantages of the method were the weight of the apparatus and the expense. The cost of gas and oxygen and sufficient ether was about $10 \mathrm{~s}$. to $12 \mathrm{~s}$. per hour.

The PResident noted the remarkable absence of shock in some of his operations-e.g., in resection of septum and laryngo-fissure, the latter requiring a good deal of manipulation. He accounted for it by the fact that a local anæsthetic was always used.

Captain BoyLE said that the amount of experience needed depended entirely upon the personality of the administrator. Some learned the method very quickly. He thought the cost was about $7 s$. $6 l$. per hour. The apparatus weighed about $65 \mathrm{lb}$. There was no need to heat the gas, as it was heated by patient's breathing. If the gas ran out it was easy to pass the oxygen through the ether and give that combination for the remainder of the operation. 